Owing to his restless state the optic discs could not be examined. On the next morning antrectomy was performed on the left side. The antrum was found to be full of inspissated pus, and on removing this the antral roof could be seen to be eroded and dark in colour. A grooved probe passed easily through the eroded tegmen antri into the temporosphenoidal lobe of the brain and pus issued freely by its side. Seeing that I had to deal with a temporo-sphenoidal abscess I trephined the squamous bone just above the external auditory meatus and with cutting forceps removed the bone between the trephine opening and the perforated antral roof. The dura mater was next reflected and the underlying brain tissue incised, and an abscess containing about two ounces of stinking green pus was exposed. The abscess cavity was gently scraped with a spoon, and when all the broken - down brain tissue had been removed, it was cleaned with antiseptic wool, filled with iodoform emulsion, and drained. The middleear was then cleared of its contents and the wound dressed in the usual way. For three days after the operation there was little improvement. He was very restless, got no sleep, and was constantly shouting. The temperature did not go down, and the head became retracted. Notwith:standing these unfavourable symptoms he was more conscious, being able to answer questions; and he could take plenty of milk. On the night of the third day from the operation he had a severe fit and became quite unconsciousshouting and moaning in a most distressing manner. The following morning, being no better, I re-opened the wound and enlarged the trephine opening backwards, when a second abscess, smaller than the first, and occupying an independent portion of the temporo-sphenoidal lobe, was discovered, cleaned out, and filled with iodoform. He bore the operation badly, and it was considered doubtful if he would rally.

His subsequent career was uneventful. He recovered consciousness and strength and at the end of three weeks was able to leave his bed. He is now quite well, except for his deafness, which he assures me is not greater than before operation.

Sheffield.

\section{TEN CASES OF PHTHISIS.}

\section{By LOUIS VINTRAS, M.D. DURH., B.Sc. Paris, PHTSICIAN TO THE FRENCH HOSPITAL.}

HAVING devoted some years to the study of this particular disease I have been more and more struck by the importance the general symptoms assume as cases progress to the detriment of the local symptoms, and I have gradually come to look upon phthisis, whether tuberculous or non-tuberculous, more as a disease of general nutrition (acute adynamia) than as a purely lung affection. Following up this theory I planned a system of treatment which should have in view the re-establishment of the physiological integrity of the system. For Nature seems to have given us indications as to the treatment of this disease in showing the great influence certain physiological processes have in checking its progress. A phthisical woman who becomes enceinte finds a great improvement in her condition during the whole time of her childbearing; again, one of the most frequent symptoms present in cases of this disease occurring in young women is the cessation of the menses, which return as soon as the condition shows a marked improvement. With the digestive organs we find an analogous fluctuation of symptoms, and this, not owing to any functional disorder, but merely from the general trophic incompetency. Thus it becomes apparent that any line of treatment which would have in view the restoration of the various physiological processes in phthisical subjects could at least claim to be rational. That such a line of treatment properly carried out can not only relieve, but also cure, even advanced cases of phthisis will be seen by the summary of the following ten cases.

CASE 1.-The patient was a young women aged twentysix years, whom I was called to attend while in the country during the summer of 1894. She had an attack of hæmoptysis and was suffering at the time from quinsy; she was under the impression that the blood came from her throat. On examining her I found she had some old-standing lung trouble and this the history she gave me fully confirmed. When her throat symptoms had subsided I made a careful examination of her chest and found that there was dulness over both apices with impaired entrance of air, while in the middle of the right back, between the fourth and fifth ribs, close to the spine, were unmistakable signs of a cavity. The expectoration, which was often blood-stained, was very tenacious and at times entirely purulent. With rest, a judicious diet, and suitable medicines she improved slowly at first, then more rapidly as the intense weakness was gradually overcome. She was a person of very active habits, passing much time in visiting the poor of her parish; and knowing that as soon as she felt better she would return to her old occupations I advised her to pass the autumn ard the winter in the south of France, which she finally agreed to do. I saw her as she passed through London in the spring on her return from Cannes, when she had gained ground wonderfully, the cough being very slight and the physical signs having almost entirely cleared up, the only thing remaining being a patch of dulness over the seat of the cavity. I have had occasion to see her several times since, and though the cough sometimes returns for a week or so and she is naturally somewhat weak she enjoys very fair health.

CASE 2.-A man aged forty years was admitted to the French Hospital on Aug. 24th, 1894. He was then suffering from advanced phthisis. His illness dated back some months, and as he had worked up to the last he was then very emaciated and in an exhausted condition. Both lungs were affected, there being signs of cavities at both apices. He was unable to leave his bed and could only take slight nourishment; the night sweats were very profuse, and his sheets had to be changed once or twice during each night. At first his condition seemed so bad that there was little hope of improvement. On Aug. 29th he was ordered two hot saline baths a week, with a view of checking the profuse night sweats. In a fortnight this distressing symptom had so far diminished that the patient could sleep comfortably. The baths were increased to three a week, and the patient's general condition exhibited a marked improvement. His appetite returned and he was able to take the ordinary diet of the hospital; the night sweats soon completely disappeared, and he began to gain weight. The local symptoms, however, remained in statu quo. By Oct. 15th the patient was so much better that he left the hospital against strong advice. In the last month he had gained $2 \mathrm{lb}$. in weight.

CASE 3.-This patient was a Greek aged twenty-seren years, who had been in England for eleven months and had been coughing for nine months, when he came among the out-patients to the French Hospital in November, 1894. He had had a slight hæmoptysis six months previously. Sometimes the expectoration was very copious. The cough would be better one week and worse the next; he was losing flesh and the night sweats were troublesome. There was deficient entrance of air at the right apex, with a patch of dulness at the lower right scapular region. There were râles present in the upper part of the left lung and much pain on that side. Pus cells and epithelial cells with some blood cells were present in the sputum, but I could find no bacilli. Under a course of hot saline baths and suitable diet he improved at first, but early in December he caught a chill and became much worse, losing between four and five pounds in weight in one week. He was admitted into the hospital, and under careful treatment, strict dietary rules, and attention to personal hygiene he became rapidly better. The cough ceased, and by the end of January he was well enough to leave the hospital. I obtained the consent of his employers that he should be sent to their station in the West Indies, and he remained there until the following November, when he returned to England. The improvement had maintained itself and he had been free from the cough during all the time he had been away. There was a good entrance of air all over the right lung, a slight deficiency in the entrance at the left apex, and some signs of consolidation opposite the third left costal cartilage. Since his arrival in England he had coughed a little; however, he was only passing through London and was about to return for good to his native country.

CASE 4.-The patient, a man aged thirty-two years (a Belgian), came to me in December, 1894. The cough had been troublesome for two years and almost continuous for eighteen months. At first he expectorated freely, but now the cough was mostly dry. The hrmoptysis had begun almost with the disease, streaks at first, then larger quantities. Af one time, after a course of treatment, he had been better for several months-never well. He was a strong 
looking man and had not lost flesh. There were, however, unmistakable signs of trouble at the left apex, with dulness and increased vocal fremitus over the upper part of the left back, with sharp pains on the left side. He was often sick after food and the night sweats were very troublesome. Under a course of saline baths, a strictly regulated diet, frictions daily over the chest and back and sedative cough mixtures the night sweats diminished and the symptoms subsided. There had been no blood in the sputum since the beginning of the treatment and only a trace one day towards the end of December. Tonics and exercise now supplemented the above treatment, and by the end of January he felt so well that he ceased the treatment. I had occasion to see him since for some other trouble and his condition remained highly satisfactory. In June he had a slight return of the cough and night sweats and again put himself under my treatment, when the symptoms rapidly disappeared. Since then $\mathrm{I}$ have not seen him.

CASE 5.-The patient was a woman aged twenty-eight years, who was admitted to the French Hospital on Jan. 7th, 1895, when she was found to be suffering from advanced phthisis, both lungs being involved. She presented the following symptoms: a hard cough, copious purulent expectorations, pain over the front of the chest, especially marked on the left side, and dyspncea. She had spat blood on several occasions, and had been gradually getting worse for the last three months, having been obliged to relinquish all occupations. She was very cachectic and had been rapidly losing flesh. There were present dyspeptic symptoms, night sweats, leucorrhœa, and slight diarrhcea. Menstruation had ceased for some months. The respiratory sounds were harsh and ierky over both apices, being puerile in the remaining parts of the right lung, and accompanied by moist crackling sounds over the left lung. On percussion there was deficiency of resonance over both apices, more marked over the left. The throat was also affected, the voice being hoarse. For weeks the patient lay in bed hovering between life and death, and it seemed as though she could only live for a few days. Towards the beginning of February it was decided to try a course of hot saline baths, notwithstanding the apparent hopelessness of the case. From the beginning the patient improved, and soon the improvement was rapid. By the end of February she could remain up part of the day. In March the expectoration was scanty and frothy, the congh was fitful, the pain in the chest had disappeared, and the appetite was good; there were no night sweats and the physical signs were clearing up. On the 14th she left the hospital. She weighed $99 \mathrm{lb}$. on admission and $106 \mathrm{lb}$. on leaving. She attended the hospital regularly until September, and in April the catamenia returned for the first time since the beginning of her illness. From this time she made rapid strides towards recovery, and though she was not unwell again for two months, from July she became quite regular. After September she ceased attending the hospital. I saw her again in February of this year, when she came about a slight return of the leucorrhoa. She had been quite well during the winter.

CASE 6-A man aged twenty.seven years was admitted to the French Hospital in May, 1895. He had marked phthisis of two years' standing, complicated with bronchitis, night sweats. cachectic appearance, and dyspeptic symptoms. He had spat blood on several occasions, but only in very small quantities. When the bronchitis subsided there were suspicious signs present at the upper part of both lungs, but nothing very definite. Inder the same treatment as in the other cases he got rapidly better and left the hospital early in July.

CASE 7.-A married woman aged twenty-five years came to see me in January of this year. Four years ago she had influenza, having been quite well before; she had "inflammation of the lungs" (?) at the time of the influenza and was in bed for a fortnight. She had been married three and a half years. The hæmoptysis began three years ago, when she coughed up about a tablespoonful of blood; after that it returned at quick intervals. Night sweats began three months ago. She had lost flesh rapidly. There were loud harsh râles at the left apex and a prolonged expiratory sound. She had been following the treatment regularly since she first saw me and had greatly improved. She bad gained weight and had a good appetite, enjoying her food. She had been regular all through, but used to suffer great pain at the time of her periods; that pain had now quite disappeared. She was sometimes free from the cough for weeks together. In April whe had a return of the hemontysis, spitting small quantities of blood for several days, but otherwise had had no bad symptoms. She was of a very nervous, almost hysterical, temperament, and most erratic in the way she carried out her treatment. She afforded a striking example of the necessity for incessant care and constant supervision in dealing with these cases, as any laxity on her part in the observance of the details of the treatment was followed by a loss of one or two pounds weight in a few days, thus destroying the effect of many weeks of care and perseverance.

CASE 8 - This patient, a French woman aged thirty-two years, was taken ill last January. The cough came on little by little. She was treated medically, with no result, and spent three weeks in Folkestone, but derived no benefit from her stay. The cough became very persistent and was accompanied by much expectoration, which was thick and greenish. There was acute pain over the front of the chest, especially on the left side, and she had no appetite. There had been no night sweats and no hæmoptysis. She had always been regular, but had lost "too much" since she bad been ill. At the left apex was a large cavernous area, with râles and sonorous rhonchi distributed over all the upper part, and hyper-resonance at the front and back. On the right side there was slight sibilant rhonchi at the apex. She looked worn, and stated that she had been losing flesh very quickly of late. She came with the out-patients of the French Hospital two months ago. She, however, made little progress, as she continutd to work, and I advised her to enter the hospital, which she did. She has done exceedingly well under treatment, and her present condition is as follows. The hyper-resonance is limited; there are but very few râles; the cough hardly troubles her; the expectoration, instead of being greenish or yellow, has become white and frothy; the quantity is much less, she sleeps well, feels stronger, and looks much brighter, her face having entirely lost its anxious, almost haggard appearance.

CASE 9.-This patient, a man aged twenty-five years (an Ita'ian), dated his illness back from October last year. The hard persistent cough, with thick, ropy expectoration, improved at times, then became worse, but never left him entirely. The expectoration became thicker and in December be had copious night sweats. He had not lost flesh and had had no hæmoptysis. He had been three years in England, and had been ill each winter, but on previous occasions the cough had only lasted for a month or so. He came to my consultation in February. There was hyperresonance over the left apex and a harsh, blowing sound. He has been attending regularly since and is now much better; he has gained in weight, the cough has almost entirely disappeared, and the physical signs have improved markedly.

CASE 10.- The last case, that of a young Swiss, I mention, though he bas only been under treatment for a month, on account of the apparently total absence of physical signs. The hacking cough, the nummular, pus-caked expectorations, the history of hæmoptysis, night sweats, and loss of flesh, the typical cachexia, and the pains in the chest are all present, but on listening to the chest nothing definite can be made out. Under treatment the patient is doing well.

It will thus be seen that all these cases have derived great benefit from the line of treatment adopted and that several have got well. These results have been obtained under the most unfarourable conditions for the treatment of such a disease as phthisis, most of the patients having worked as long as they had any strength left and others having continued their occupation during their treatment. Again, many of them belong to a class who have only the bare necessities of life, and in phthisis more than in any disease the ultimate welfare of the patient depends on the treatment and on little comforts that money alone can give. If, then, such results are obtainable under these conditions, how much more surely could they be obtained for those who have both the time and the means to undergo a minute and necessarily lengthy treatment demanding both perseverance and intelligence on the part of the patient? lrom the very nature of this disease it is apparent that with any case which is allowed to go too far a phase will come when no treatment can be of any avail, and with the particular method $I$ advocate cases of galloping phthisis, for instance, are too rapid to allow of its effects being exhibited, but in the chronic form of the disease, even with serious lung lesions and advanced adynamia, this method of treatment holds out to the patient a very fair promise of recovery.

II anorer-square, $W$ 